\title{
Remediation of Heavy Metals Polluted Soil Using Metal Insolubilizing Materials
}

\author{
Shinya Inazumi ${ }^{*}$, Ken-Ichi Shishido², Supakij Nontananandh ${ }^{3}$, Kosuke Moriiwa ${ }^{4}$ \\ ${ }^{1}$ Department of Civil Engineering, College of Engineering, Shibaura Institute of Technology, Tokyo, Japan \\ ${ }^{2}$ TOMEC Corporation, Tokyo, Japan \\ ${ }^{3}$ Department of Civil Engineering, Faculty of Engineering, Kasetsart University, Bangkok, Thailand \\ ${ }^{4}$ Division of Architecture and Civil Engineering, Graduate School of Engineering and Science, Shibaura \\ Institute of Technology, Tokyo, Japan \\ Email: ^inazumi@shibaura-it.ac.jp, shishido@tomec.jp, fengskn@ku.ac.th, ah14215@shibaura-it.ac.jp
}

How to cite this paper: Inazumi, S., Shishido, K.-I., Nontananandh, S. and Moriiwa, K. (2018) Remediation of Heavy Metals Polluted Soil Using Metal Insolubilizing Materials. Journal of Environmental Protection, 9, 770-789.

https://doi.org/10.4236/jep.2018.97048

Received: May 29, 2018

Accepted: June 18, 2018

Published: June 21, 2018

Copyright $\odot 2018$ by authors and Scientific Research Publishing Inc. This work is licensed under the Creative Commons Attribution International License (CC BY 4.0).

http://creativecommons.org/licenses/by/4.0/

\begin{abstract}
Heavy metal ions, one kind of harmful substance, may exist in the soil irrelevant to artificial development, and soil contamination, due to soil and rock containing these naturally derived heavy metals, has recently become apparent. Thus, in an amendment that came into effect in 2010 of Japan, the scope of countermeasures and regulations for contaminated soil was amended to "contaminated soil derived from artificial development" and "naturally derived contaminated soil". When naturally derived contaminated soil is encountered during the carrying out of construction work, countermeasures against this type of soil contamination are necessary. In this research, new metal-insolubilizing materials are developed in order to improve the insolubilization treatment which is one method for treating contaminated soil. Specifically, tests are conducted to clarify the insolubilization effect on heavy metals, and the insolubilization mechanism is chemically and mineralogically discussed.
\end{abstract}

\section{Keywords}

Insolubilization Treatment, Insolubilization Mechanism, Metal-Insolubilizing Material, Leaching Test, Contaminated Soil

\section{Introduction}

In recent years, soil contamination caused by naturally occurring heavy metals in the soil has become a problem. One solution is to restore this contaminated 
soil and put it to practical use. Based on the Soil Contamination Countermeasures Act (Act No. 53 of 2002) by Ministry of the Environment, Government of Japan [1], the restoration of contaminated soil involves satisfying the environmental quality standards for the amounts leached in soil and content in soil. The most reliable method for restoring contaminated soil is to purify it by soil washing. Purification is a very attractive and highly effective method for dealing with contaminated soil. However, it is not very practical because it is economically inefficient and can be applied only under limited conditions, such as when the clay component of the soil is extremely low [2]. At present, there are few efficient and economical methods for removing heavy metals, namely, inorganic pollutants, from soil. As with excavation removal, it is common for contaminated soil to be brought to a treatment facility and processed. However, there is a limit to the amount of contaminated soil that can be accepted at existing disposal sites, and establishing new disposal sites is difficult due to the opposition of neighboring residents and the strengthening of regulations. In view of the recent circumstances, it has become necessary to avoid treatment by landfilling with contaminated soil, to appropriately treat the target soil right at the excavation site, and to create technologies for recycling this soil as earth and sand. Thus, researching new methods for removing harmful substances from soil at a low cost is important.

The focus is now being placed on an insolubilization treatment which can improve contaminated soil while satisfying these conditions. Insolubilization treatment means that when inorganic contaminants, such as heavy metals, are contained in the soil and contaminate it, they are chemically insolubilized by mixing in safe and harmless metal-insolubilizing materials; this eliminates the risks of toxicity. Insolubilization treatment is more economical than other treatments. It does not require the contaminated soil to be transported away from the site. The risk of contamination diffusion at the time of movement is low, and it has advantages such as low energy consumption. In addition, metal-insolubilizing materials which contain an inorganic mineral as the main raw material cause less of an environmental burden than cementitious material. However, with conventional inorganic mineral-based metal-insolubilizing materials, the insolubilization effect is exerted only for certain heavy metals. In some cases, it is not possible to insolubilize plural heavy metals. In addition, considering the environment in which treated soil is placed, it is important for the $\mathrm{pH}$ level to be kept constant over the long term in order to exert the insolubilization of harmful substances over the long term.

In this study, upgrade of metal-insolubilizing materials proposed can improve the instability of the insolubilization effect due to the type of heavy metal, which is one of the problems of conventional metal-insolubilizing materials. Specifically, the aims are to conduct leaching tests on the insolubilization effect on heavy metals, to elucidate the insolubilization mechanism from the test results, and to ensure the long-term stability of the insolubilization treatment, as shown in Figure 1. 


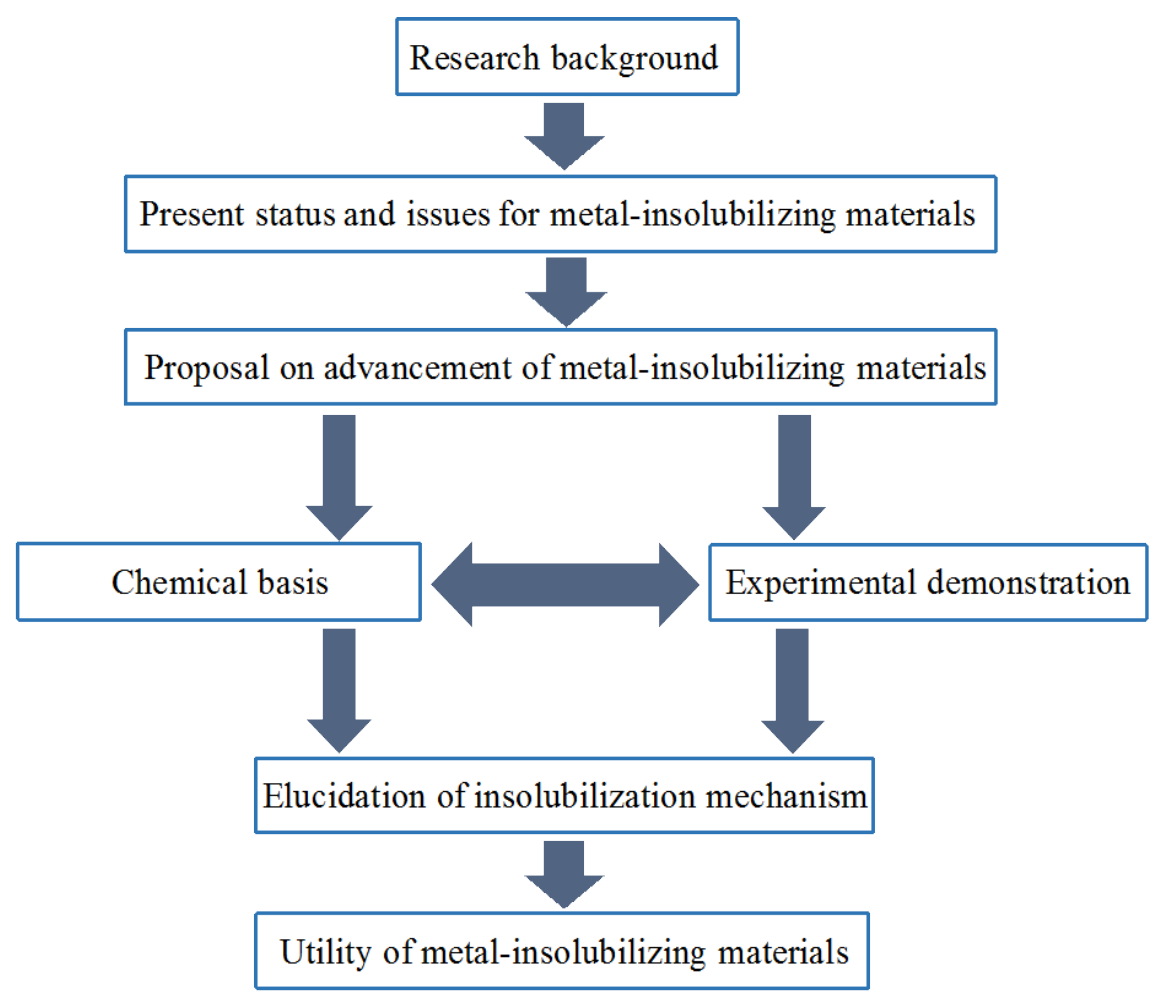

Figure 1. Purpose and flow of this research.

\section{Insolubilization Treatment for Soil Contaminated with Heavy Metals}

\subsection{Concept and History of Soil Contamination}

Soil contamination means that the soil and the groundwater contain harmful chemical substances which can cause adverse effects on people's health, the living environment, and the ecosystem [2] [3]. Soil contamination is roughly divided into two categories, artificial soil contamination due to factory operations and mining development, and soil contamination caused by substances deposited in nature.

The history of soil contamination in Japan dates back to the Meiji era. The oldest soil contamination problem is the Ashio copper mine pollution incident, which occurred during the modernization period just after the Meiji Restoration. In this incident, heavy metal ions that were contained in waste stone, and so on, generated by mining, flowed into the Watarase River, and when the river flooded, soil contamination by these heavy metal ions was widespread [4].

In addition, Itai-Itai disease, one of the Four Big Pollution Diseases in Japan, is caused by the soil and groundwater contamination problem brought about by cadmium ions, which are a kind of heavy metal ion [5].

As previously stated, there are cases where naturally derived heavy metal ions exist regardless of artificial development. In volcanic countries, like Japan, igneous rocks are distributed nationwide, and volcanic sedimentary rocks are scattered on the surface due to crustal deformation [6]. Heavy metal ions may be 
contained in these volcanic sedimentary rocks; such soils are regarded as soil contaminated with naturally derived heavy metal ions. As a result of the revision of the law enacted in 2010, the scope of countermeasures and regulations for contaminated soil was revised as "contaminated soil derived from artificial development" and "contaminated soil derived from nature", as shown in Table 1. Therefore, when contaminated soil derived from nature is encountered in construction work, a countermeasure is necessary [3].

\subsection{Soil Contamination Countermeasures Act}

In Japan, the Soil Contamination Countermeasures Act (Act No. 53 of 2002), Ministry of the Environment, Government of Japan was enacted in 2003 to grasp the soil contamination status by volatile substances, heavy metal ions, agricultural chemicals, and so on, which are designated as hazardous substances, and to prevent damage to human health due to contaminated soil. However, regarding management and countermeasures in cases where soil contamination is found by voluntary investigations and not based on the law, despite the promising effect of blocking the intake route for harmful substances, such as by an "embankment" or "containment", excessive countermeasures, such as "excavation removal", have frequently been taken due to the law. In this way, since the inappropriate treatment of contaminated soil was frequently conducted and the cases of excavation removal increased, the Soil Contamination Countermeasures Act was amended in 2010 [3] [7].

\subsection{Soil Contaminated with Heavy Metals and Environmental Quality Standards}

The Ministry of the Environment assumes two routes of intake to people of designated hazardous substances, "direct intake" and "intake via underground water".

Environmental quality standards for content in soil (Environment Agency Notification No. 19) based on the Soil Contamination Countermeasures Act have been established for risks assuming the direct intake of hazardous substances. In the case of contaminated soil that exceeds the environmental quality standards for the content in soil, in principle, measures, such as embankments, are taken. The environmental quality standards for the amount leached in soil (Environment Agency Notification No. 18) based on the Soil Contamination Countermeasures Act have been established as standards for risks assuming the

Table 1. Amendment of soil contamination countermeasures act (Act No. 53 of 2002), ministry of the environment, government of Japan.

\begin{tabular}{lcc}
\hline \multirow{2}{*}{ Necessity of Countermeasures } & \multicolumn{2}{c}{ Soil Contamination Countermeasures Act } \\
\cline { 2 - 3 } & Before amendment & After amendment \\
\hline Contaminated soil derived from artificial development & Necessary & Necessary \\
Contaminated soil derived from nature & - & Necessary \\
\hline
\end{tabular}


intake of hazardous substances via groundwater. In the case of contaminated soil that exceeds the environmental quality standards for the amount leached in soil, in principle, countermeasures, such as in-situ containment, are taken. However, in view of the contamination situation, other countermeasures can be taken at the request of the landowner, as shown in Table 2.

In Table 2, if designated hazardous substances exceed the environmental quality standards for the content in soil, insolubilization treatment cannot be applied. However, when considering the risk of intake of harmful substances via groundwater, insolubilization treatment can be applied. Insolubilization treatment is very effective against low-concentration contaminated soil that satisfies the environmental quality standards for the content in soil of designated hazardous substances, and does not exceed the second level standards for the amount eluted soil which are larger from 3 to 30 times than the first level standards for the amount leached in soil. Furthermore, this method is also very effective against naturally derived contaminated soil [3] [7]. In summary, insolubilization treatment suppresses the leaching of heavy metal ions from soil for which the content of the heavy metal ions in the soil is not so high, but the amount of leaching into the groundwater exceeds the environmental quality standards.

\subsection{Insolubilization Treatment and $\mathrm{pH}$}

The three main types of insolubilizing materials are cement-based materials using cement, lime-based materials mainly containing quick lime and slaked lime, and metal-insolubilizing materials mainly containing inorganic minerals. There is no difference in performance among the cement-based materials, lime-based materials, and inorganic mineral-based materials from the viewpoint of insolubilization against designated hazardous substances (heavy metal ions), although there is a difference in the $\mathrm{pH}$ levels (hydrogen ion exponents) in the soil after the insolubilization treatment, as shown in Table 3. Therefore, depending on the combination of contaminated soil and metal-insolubilizing material, the soil after insolubilization treatment can be reused as ground material in some cases. Insolubilization treatment with inorganic mineral-based metal-insolubilizing materials has the advantage of inducing the $\mathrm{pH}$ value.

Table 2. Countermeasures of designated hazardous substances.

\begin{tabular}{lll}
\hline & Countermeasures in principle & Other countermeasures \\
\hline $\begin{array}{l}\text { Exceeds the environmental quality } \\
\text { standards for the content in soil } \\
\text { (Prevent direct intake) }\end{array}$ & Embankments & $\begin{array}{l}\text { Pavement } \\
\text { No trespassing } \\
\text { Soil replacement }\end{array}$ \\
$\begin{array}{l}\text { Exceeds the environmental } \\
\text { quality standards for the amount } \\
\text { leached in soil (prevent intake } \\
\text { via underground water) }\end{array}$ & In-situ containment & $\begin{array}{l}\text { In-situ insolubilization } \\
\text { Backfill insolubilized soil } \\
\end{array}$ \\
\end{tabular}


Table 3. Insolubilization effect and $\mathrm{pH}$ change of each metal-insolubilizing material.

\begin{tabular}{ccc}
\hline & Insolubilization effect & $\mathrm{pH}$ after insolubilization treatment \\
\hline Cement-based materials & Effective & Consistently alkaline \\
Lime-based material & Effective & Consistently alkaline \\
Metal-insolubilizing materials & Effective & Depending on the situation \\
\hline
\end{tabular}

\subsection{Long-Term Weather Resistance of Soil after Insolubilization Treatment}

In soil subjected to insolubilization treatment, the heavy metal ions must be kept in the soil for a long time so that they do not dissolve again. However, after the insolubilized soil is backfilled to the ground, the heavy metal ions immobilized in the soil may be re-eluted along with the changes in the $\mathrm{pH}$ of the soil due to rainwater or external factors, and so on. Since cement-based materials and lime-based materials exert and maintain their insolubilization effect under alkaline conditions, heavy metal ions are re-eluted if the $\mathrm{pH}$ of the insolubilized soil decreases. This phenomenon is called neutralization, and heavy metal ions may leach into the surrounding soil and groundwater due to the neutralization of the insolubilized soil.

Therefore, when insolubilizing with a cement-based material, a cover soil is applied to the surface layer of the backfilled soil to prevent the re-elution of the heavy metal ions due to soil neutralization [8]. Similarly, even in insolubilization using a metal-insolubilizing material, it is necessary to apply a countermeasure against stimulation to the soil $\mathrm{pH}$ due to external factors, such as acid rain, and treat the soil so that the heavy metal ions do not dissolve.

\section{Experimental Study on Insolubilization Effect of Metal-Insolubilizing Material}

\subsection{Overview}

As mentioned earlier, due to the amendment of the Soil Contamination Countermeasures Act in 2010 [3] [7], countermeasures are now required for the development of contaminated soil derived from nature which had not been regulated in the past. Regarding the improvement of contaminated soil derived from nature, the contaminated soil to be improved is widely distributed in many cases, and increases in the environmental load and processing costs are expected in the case of insolubilization treatment with conventional cement-based or lime-based materials. Therefore, it is necessary to carry out mineral stabilization (insolubilization treatment) on construction-generated soil in order to reduce the transportation risk, costs, and environmental load.

In this study, leaching tests by Environment Agency Notification No. 46, announced in 1991, used to determine the insolubilization effect [9]. The contaminated soil targeted in this study contains naturally derived heavy metals and the like. In order to investigate the insolubilization effect of the metal-insolubilizing material on the contaminated soil, leaching and $\mathrm{pH}$ tests were 
performed. Moreover, in order to verify whether hazardous substances insolubilized by the metal-insolubilizing material could be kept in a stable state for a long time and could withstand the change in $\mathrm{pH}$ due to the aging of the soil, acid addition leaching tests were performed based on acid rain precipitation equivalent to 500 years recommended by the Geo-Environmental Protection Center (2008). After insolubilization treatment, it was possible to cast steel pipe piles and to drive concrete, and so on, into the soil via construction work. At this time, the improved soil may be affected by alkali [10]. Therefore, considering the stimulation by alkali, alkali addition tests, recommended by the Geo-Environmental Protection Center (2008) were conducted and the long-term weatherability against alkali was verified.

\subsection{Characteristics of Metal-Insolubilizing Materials}

Two kinds of metal-insolubilizing materials, A and B, were used in this study. Metal-insolubilizing material A is composed mainly of calcium, silicon, and aluminum components, as shown in Table 4. Metal-insolubilizing material B newly incorporates a magnesium component into metal-insolubilizing material $\mathrm{A}$, and the magnesium becomes one of the main components instead of the silicon, as shown in Table 5. By adding these materials to contaminated soil, the insolubilization effect brought about by the minerals produced by a chemical reaction can be expected.

\subsection{Leaching Test}

According to the environmental quality standards for the amount leached in soil (Environment Agency Notification No. 18) based on the Soil Contamination Countermeasures Act, the leaching test (specified as Environment Agency Notification No. 46) shall be conducted for lead $(\mathrm{Pb})$, arsenic (As), selenium (Se),

Table 4. Compounding ratio of metal-insolubilizing material A.

\begin{tabular}{cc}
\hline & \multicolumn{1}{c}{ Compounding ratio (\%) } \\
\cline { 2 - 2 } Main components & Metal-insolubilizing material A \\
\hline $\mathrm{CaO}$ & 40 \\
$\mathrm{SiO}_{2}$ & 40 \\
$\mathrm{Al}_{2} \mathrm{O}_{3}$ & 20 \\
\hline
\end{tabular}

Table 5. Compounding ratio of metal-insolubilizing material B.

\begin{tabular}{cc}
\hline & \multicolumn{1}{c}{ Compounding ratio (\%) } \\
\cline { 2 - 2 } Main components & Metal-insolubilizing material B \\
$\mathrm{MgO}$ & 10 \\
$\mathrm{Al}_{2} \mathrm{O}_{3}$ & 60 \\
$\mathrm{SO}_{3}$ & 15 \\
\hline
\end{tabular}


and cadmium (Cd) by a measurement method that is compatible with the type of designated hazardous substances [9].

The batch typed leaching test method, which is used as the general evaluation method for the leaching test in public works, is employed here, as shown in Figure 2 [11] [12] [13].

\section{4. pH Test}

The $\mathrm{pH}$ test (suspension method) is carried out according to the "JGS 0211-2009" standard set by the Japanese Geotechnical Society [14]. The test method stipulates that the $\mathrm{pH}$ be measured as a fluid in a state at which the soil and the water are suspended, and targets particles with a particle size of $10 \mathrm{~mm}$ or less.

\subsection{Long-Term Weather Resistance Test}

In this research, a long-term weather resistance test is carried out according to the "Relative evaluation method of $\mathrm{pH}$ stability of soil after insolubilization treatment-sulfuric acid added leaching test-slaked lime added leaching test" guidelines established as technical standard No. 2 of the Geo-Environmental Protection Center (2010), as shown in Figure 3. In addition, it is advisable that the test method be simple, and as much as possible, that the variation in the results of the test be decreased in order to bring a certain accuracy to the results. Therefore, test methods requiring complicated operations, such as the column test and the sequential leaching test, are not used here; the batch typed leaching test is used [11].

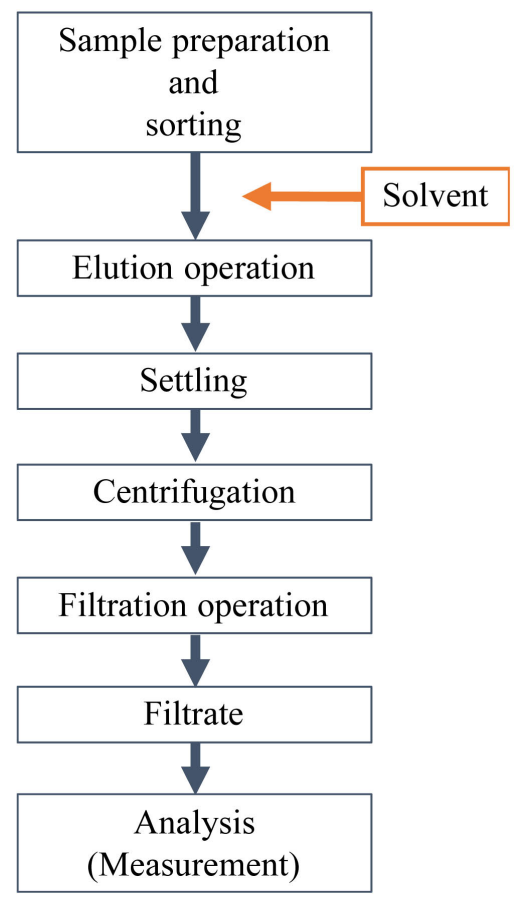

Figure 2. Flow of leaching test. 


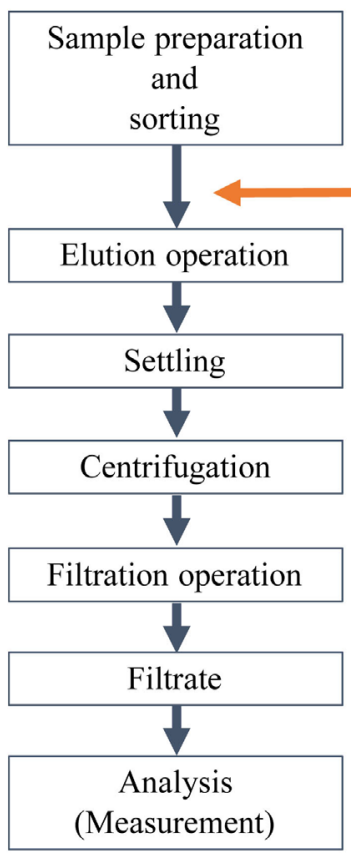

Add sulfuric acid aqueous solution or

Add slaked lime aqueous solution

Figure 3. Flow of long-term weather resistance test.

\section{Insolubilization Effect on Soil Contaminated with Multiple Types of Heavy Metals}

In order to evaluate and investigate the insolubilization effect of metal-insolubilizing materials, metal-insolubilizing material A was added to soil contaminated with multiple types of heavy metals and a leaching test and a $\mathrm{pH}$ test were conducted, as detailed in Table 6.

\subsection{Test Method and Conditions}

\section{a) Target soil}

The target soil was mudstone contaminated with multiple types of heavy metals, and the soil was acidic $(\mathrm{pH}=3.6)$ before adding the metal-insolubilizing material.

\section{b) Leaching test}

The leaching test was conducted as explained in 3.3. An inductively coupled plasma mass spectrometer (ICP-MS) was used for the test.

c) $p H$ test

The $\mathrm{pH}$ test was conducted as detailed in 3.4.

\subsection{Test Results}

\section{a) Leaching test}

The results of the leaching test are shown in Table 7 and Figure 4.

By adding metal-insolubilizing material $\mathrm{A}$, it is clear that the leaching amounts of $\mathrm{As}, \mathrm{Pb}, \mathrm{Se}$, and $\mathrm{Cd}$ are below the environmental quality standards for soil $(0.01 \mathrm{mg} / \mathrm{L})$. Regarding Cd, although the leaching amount of the target soil (raw soil) is $0.009 \mathrm{mg} / \mathrm{L}$, less than the environmental quality standard for soil, 


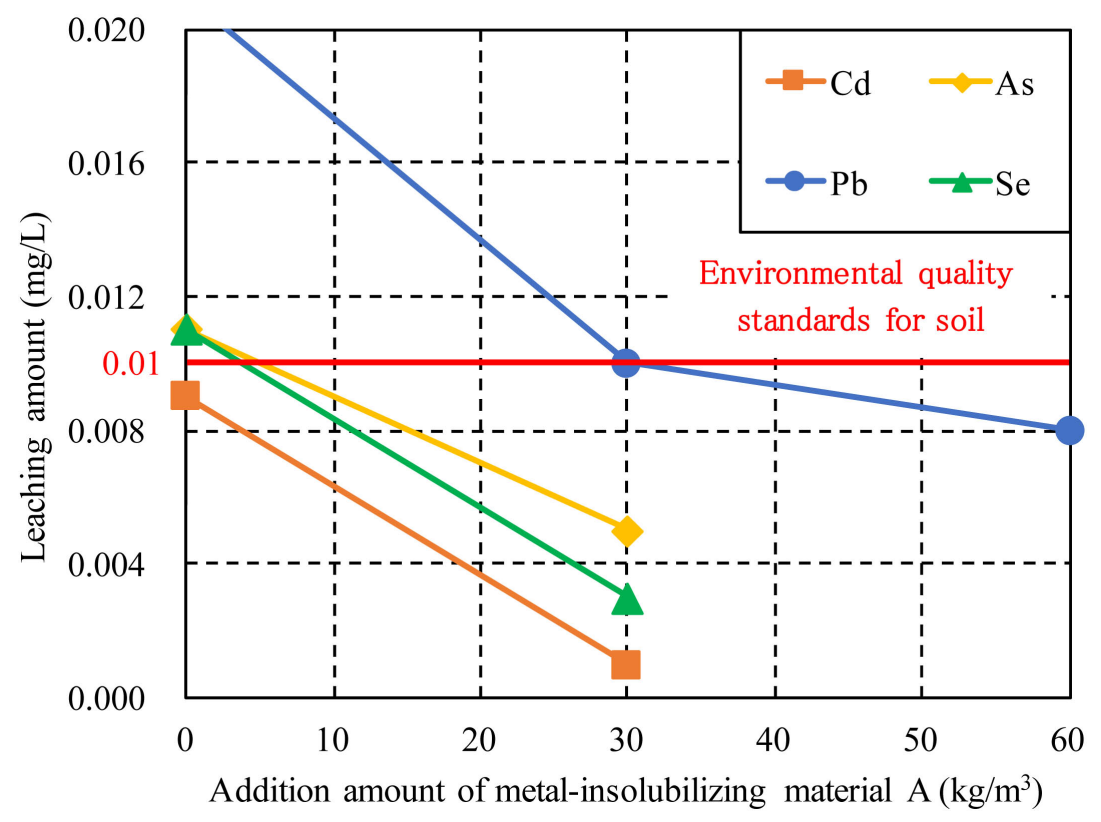

Figure 4. Results of leaching test.

Table 6. Test method and conditions.

\begin{tabular}{cc}
\hline Target soil & Mudstone \\
\hline Metal-insolubilizing material \\
Addition amount of metal-insolubilizing material \\
Leaching test method & Metal-insolubilizing material A \\
Environmental quality standards for soil & $30,60 \mathrm{~kg} / \mathrm{m}^{3}$ \\
(As, Pb, Se, Cd) & \\
$\mathrm{pH}$ test method & Soil Contamination Countermeasures Act \\
Curing period of sample & \\
\end{tabular}

Table 7. Results of leaching test.

\begin{tabular}{ccccc}
\hline & & \multicolumn{2}{c}{ Addition amount of metal-insolubilizing material A $\left(\mathrm{kg} / \mathrm{m}^{3}\right)$} \\
\cline { 3 - 5 } & & 0 & 30 & 60 \\
\hline & $\mathrm{Cd}$ & 0.009 & 0.001 & - \\
\multirow{2}{*}{$\begin{array}{c}\text { Leaching amount } \\
(\mathrm{mg} / \mathrm{L})\end{array}$} & $\mathrm{As}$ & 0.011 & 0.005 & - \\
& $\mathrm{Pb}$ & 0.021 & 0.010 & 0.008 \\
& $\mathrm{Se}$ & 0.011 & 0.003 & - \\
\hline
\end{tabular}

the leaching amount of $\mathrm{Cd}$ was greatly reduced by the addition of metal-insolubilizing material $\mathrm{A}$, and the insolubilization effect is observed. In addition, the leaching amount of $\mathrm{Pb}$ in the raw soil is $0.021 \mathrm{mg} / \mathrm{L}$. When $30 \mathrm{~kg} / \mathrm{m}^{3}$ of metal-insolubilizing material A is added, the material shows the same value as the environmental quality standard for soil; and thus, a sufficient insolubilization effect cannot be obtained. However, when $60 \mathrm{~kg} / \mathrm{m}^{3}$ of $\mathrm{A}$ is added, the 
leaching amount of $\mathrm{Pb}$ is be decreased; and thus, the insolubilization effect is observed for $\mathrm{Pb}$.

\section{b) $\mathrm{pH}$ test}

Regarding the results of the $\mathrm{pH}$ test, the $\mathrm{pH}$ of the soil after the addition of 30 $\mathrm{kg} / \mathrm{m}^{3}$ of metal-insolubilizing material A was 7.5 , whereas the $\mathrm{pH}$ of the target soil (raw soil) was 3.6. That is, although the raw soil was acidic, the soil was neutral after adding metal-insolubilizing material $\mathrm{A}$. It is thought that the neutralization reaction occurs due to the mixing with the target soil (raw soil), resulting in the increase in $\mathrm{pH}$, since the main component of metal-insolubilizing material A, such as lime, is alkaline.

\subsection{Issues for Metal-Insolubilizing Material A}

In order to maintain the insolubilization effect over a long period of time, it is necessary to evaluate and examine the insolubilization effect under external stimulus, such as from acid and alkali. When the contaminated soil is alkaline before the insolubilization treatment, there is concern that the insolubilization effect due to metal-insolubilizing material A cannot be exerted. Therefore, it is necessary to investigate metal-insolubilizing materials that do not cause the soil $\mathrm{pH}$ to become extremely acidic or alkaline after the insolubilization treatment.

\section{Insolubilization Effect Taking External Stimulus into Account}

The insolubilization effects due to the difference between insolubilizing materials $\mathrm{A}$ and $\mathrm{B}$ were examined by conducting an acid or alkali addition leaching test, which considered the long-term weather resistance, along with the leaching test and the $\mathrm{pH}$ test, as shown in Table 8.

\subsection{Test Method and Conditions}

\section{a) Target soil}

The target soil was gravel soil contaminated only with arsenic (As); the soil was alkaline $(\mathrm{pH}=11.9)$ before the metal-insolubilizing material was added.

Table 8. Test method and conditions.

\begin{tabular}{cc}
\hline Target soil & Gravel soil \\
\hline Metal-insolubilizing material & Metal-insolubilizing materials A and B \\
Addition amount of metal-insolubilizing material & $20,40,60,80 \mathrm{~kg} / \mathrm{m}^{3}$ \\
Leaching test method & Soil Contamination Countermeasures Act \\
Environmental quality standards for soil (As) & $0.01 \mathrm{mg} / \mathrm{L}$ or less \\
pH test method & Suspension method \\
Curing period of sample & 1 day \\
Acid or alkali addition leaching test & Geo-Environmental Protection Center \\
Regarding acid or alkali addition leaching test, the addition amount is only $20 \mathrm{~kg} / \mathrm{m}^{3}$
\end{tabular}




\section{b) Leaching test}

The leaching test was conducted as explained in 3.3. An inductively coupled plasma mass spectrometer (ICP-MS) was used for the test.

c) $\mathrm{pH}$ test

The test was conducted as defined in 3.4.

d) Acid addition leaching test

The test was conducted as given in 3.5.

e) Alkali addition leaching test

The test was conducted as given in $\mathbf{3 . 5}$.

\subsection{Test Results}

\section{a) Leaching test}

The results of the leaching test are shown in Table 9 and Figure 5. The insolubilization effect on arsenic (As) can be confirmed for each metal-insolubilizing material.

\section{b) $p H$ test}

The results of the $\mathrm{pH}$ test are shown in Table 10 and Figure 6.

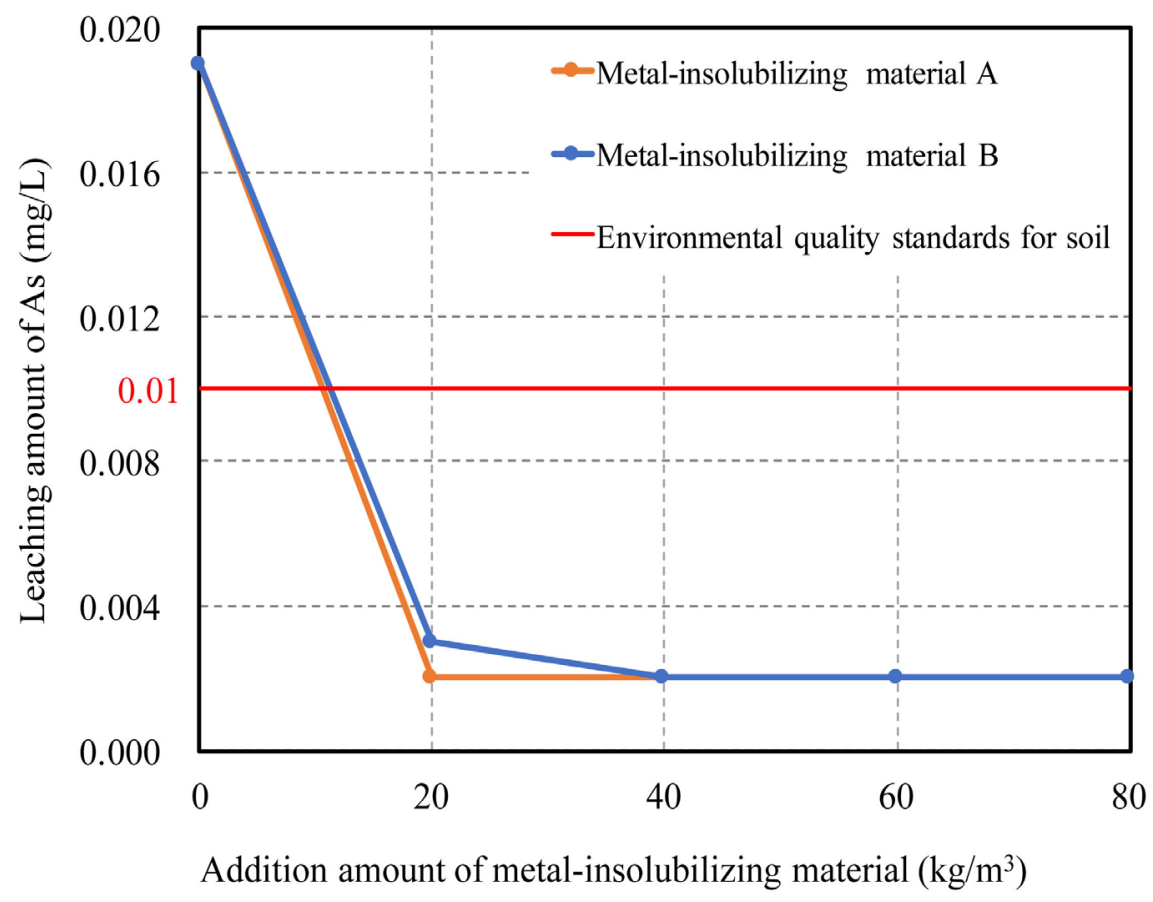

Figure 5. Results of leaching test.

Table 9. Results of leaching test.

\begin{tabular}{ccccccc}
\hline & & \multicolumn{5}{c}{ Addition amount of metal-insolubilizing material $\left(\mathrm{kg} / \mathrm{m}^{3}\right)$} \\
\cline { 3 - 7 } & & 0 & 20 & 40 & 60 & 80 \\
\hline $\begin{array}{c}\text { Leaching } \\
\text { amount of } \\
\text { As (mg/L) }\end{array}$ & Metal-insol. A & 0.019 & 0.002 & 0.002 & 0.002 & 0.002 \\
\hline
\end{tabular}




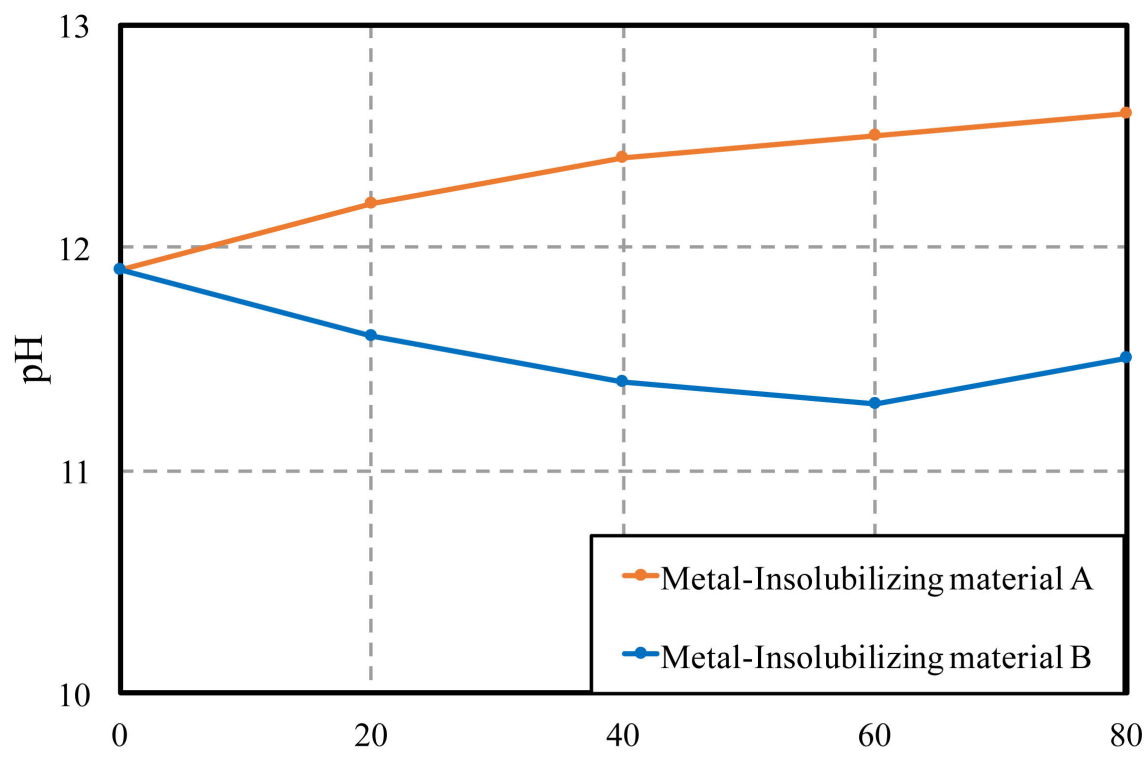

Addition amount of metal-insolubilizing material $\left(\mathrm{kg} / \mathrm{m}^{3}\right)$

Figure 6. Results of $\mathrm{pH}$ test.

Table 10. Results of $\mathrm{pH}$ test.

\begin{tabular}{ccccccc}
\hline & & \multicolumn{4}{c}{ Addition amount of metal-insolubilizing material $\left(\mathrm{kg} / \mathrm{m}^{3}\right)$} \\
\cline { 3 - 7 } & & 0 & 20 & 40 & 60 & 80 \\
\hline \multirow{2}{*}{$\mathrm{pH}$} & Metal-insol. A & 11.9 & 12.2 & 12.4 & 12.5 & 12.6 \\
& Metal-insol. B & 11.9 & 11.6 & 11.4 & 11.3 & 11.5 \\
\hline
\end{tabular}

When metal-insolubilizing material $\mathrm{A}$ is added, the $\mathrm{pH}$ of the soil rises in comparison to that before the addition. As a result, it is conceivable that the main component of metal-insolubilizing material $\mathrm{A}$ is alkaline. In addition, when metal-insolubilizing material $\mathrm{B}$ is added, the $\mathrm{pH}$ of the soil decreases in comparison to that of the target soil and the case in which metal-insolubilizing material $\mathrm{A}$ is added. As a result, the amount of the metal component, indicating the acid, is increased in metal-insolubilizing material $\mathrm{B}$ in comparison to metal-insolubilizing material $\mathrm{A}$, and it is thought that the addition of the magnesium component causes the $\mathrm{pH}$ buffering action [15].

\section{c) Acid or alkali addition leaching test}

The results of the acid or alkali addition leaching test are shown in Table 11 and Figure 7.

When the soil receives external stimulus, such as acid and alkali after adding metal-insolubilizing material $\mathrm{A}$, the leaching amount of arsenic exceeds the environmental quality standards for soil and cannot maintain the insolubilization effect. On the other hand, after adding metal-insolubilizing material $\mathrm{B}$, the insolubilization effect can be maintained. Thus, it is thought that the insolubilization effect is maintained by the $\mathrm{pH}$ buffering action because metal-insolubilizing material B contains a large amount of the magnesium component [15]. 


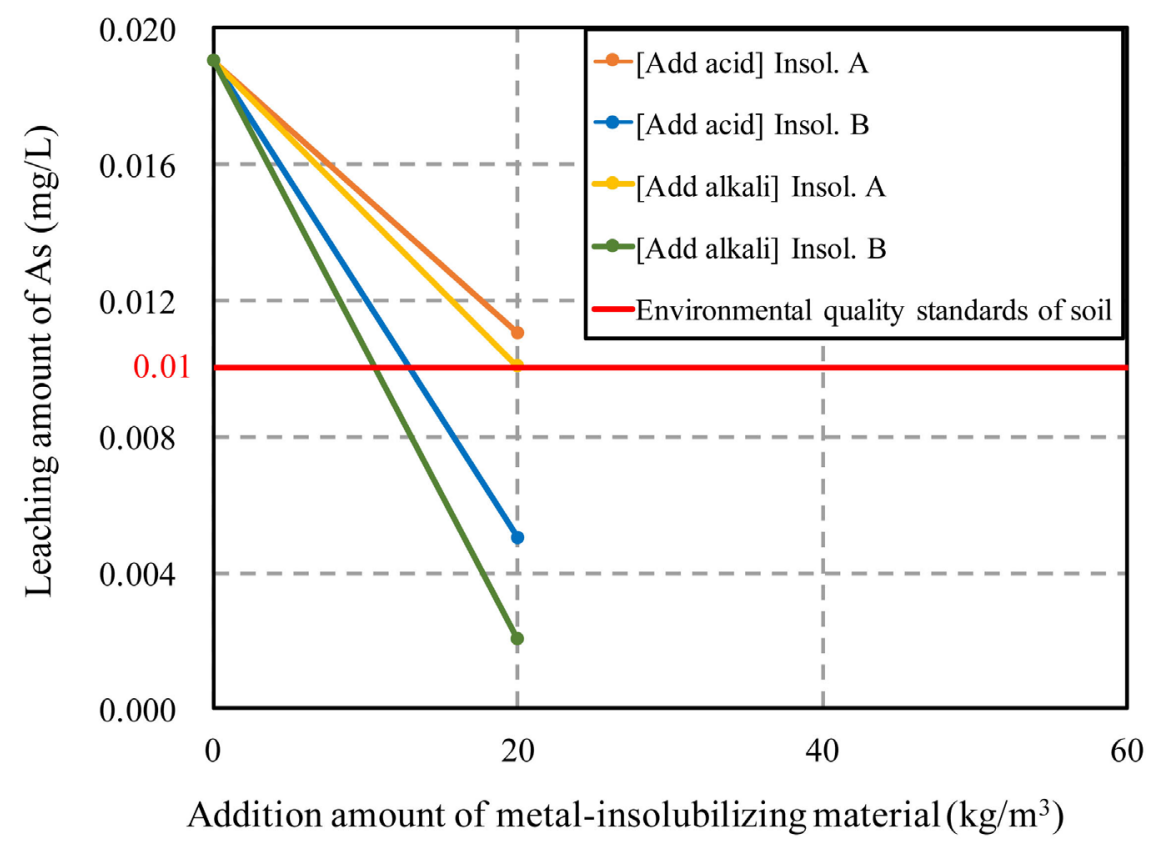

Figure 7. Results of acid or alkali addition leaching test.

Table 11. Results of acid or alkali addition leaching test.

\begin{tabular}{ccccc}
\hline & & \multicolumn{2}{c}{$\begin{array}{c}\text { Addition amount of metal-insolubilizing } \\
\text { material }\left(\mathrm{kg} / \mathrm{m}^{3}\right)\end{array}$} \\
\cline { 3 - 5 } & & 0 & 20 \\
\hline & & Metal-insol. A & 0.019 & 0.011 \\
\multirow{2}{*}{$\begin{array}{c}\text { Leaching amount } \\
\text { of As (mg/L) }\end{array}$} & Add acid & Metal-insol. B & 0.019 & 0.005 \\
& Add alkali & Metal-insol. A & 0.019 & 0.010 \\
& & Metal-insol. B & 0.019 & 0.002 \\
\hline
\end{tabular}

\section{Insolubilization Mechanism for Heavy Metals}

\subsection{Classification of Insolubilization Mechanism}

This study focuses on insolubilization by minerals. Therefore, it is necessary to clarify the mechanism. First, the reaction caused by insolubilization will be summarized. The factors of insolubilization are roughly divided into adsorption and sorption. Adsorption is divided into physisorption and chemisorption depending on the mechanism [16] [17] [18].

\section{a) Physisorption}

Physisorption is due to van der Waals' force and Coulomb's force. In particular, adsorption by Coulomb's force (electrostatic force) is called electrostatic adsorption. Such physical adsorption is also called an outer sphere complex formation reaction; it constrains the molecules and ions in the solution by the above-mentioned force and has no chemical bond [16] [17] [18]. Therefore, physisorption is weaker than chemisorption, which will be described later.

\section{b) Chemisorption}


In chemisorption, electrons are exchanged between adsorbed solutes (molecules and ions) and atoms on a solid surface, resulting in a strong chemical bond. Adsorption with such chemical bonds is also called an inner sphere complex formation reaction [16] [17] [18].

c) Sorption

Sorption is a phenomenon in which adsorption and absorption occur simultaneously. That is, molecules and ions in the solution are adsorbed on the solid surface, and the adsorbates pass through the solid surface layer and enter the inside [16] [17] [18]. In addition, when the adsorbates are incorporated into the solid, it is thought that the crystal structure of the solid changes and a rearrangement occurs. In other words, a new compound is generated, as seen in Figure 8.

\subsection{Insolubilization by Generated Minerals}

Focus is on insolubilization by various kinds of minerals based on the contents described in 6.1. From the above test results, insolubilization by metal-insolubilizing material $\mathrm{A}$ is thought to be insolubilization by schwertmannite and apatite. In addition, insolubilization by metal-insolubilizing material $B$ is thought to be insolubilization by hydrotalcite together with schwertmannite and apatite, as shown in Figure 9 and Figure 10. Therefore, the insolubilization mechanism by these minerals, generated after adding the metal-insolubilizing material, is discussed.

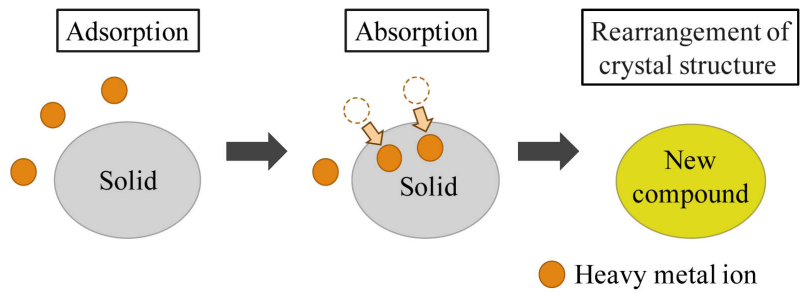

Figure 8. Image of sorption.

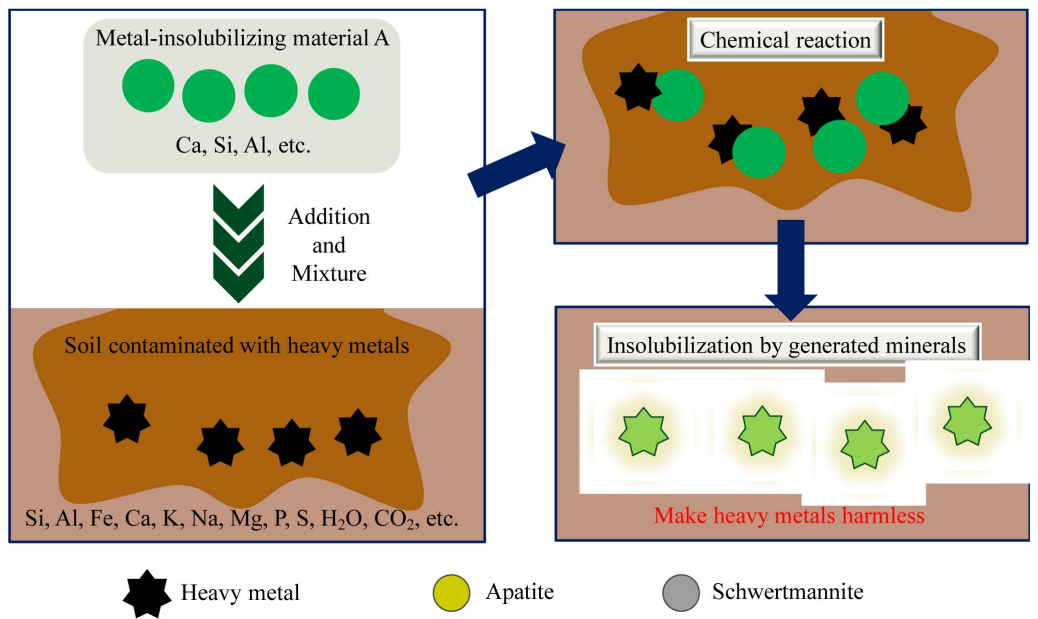

Figure 9. Insolubilization mechanism by metal-insolubilizing material A. 


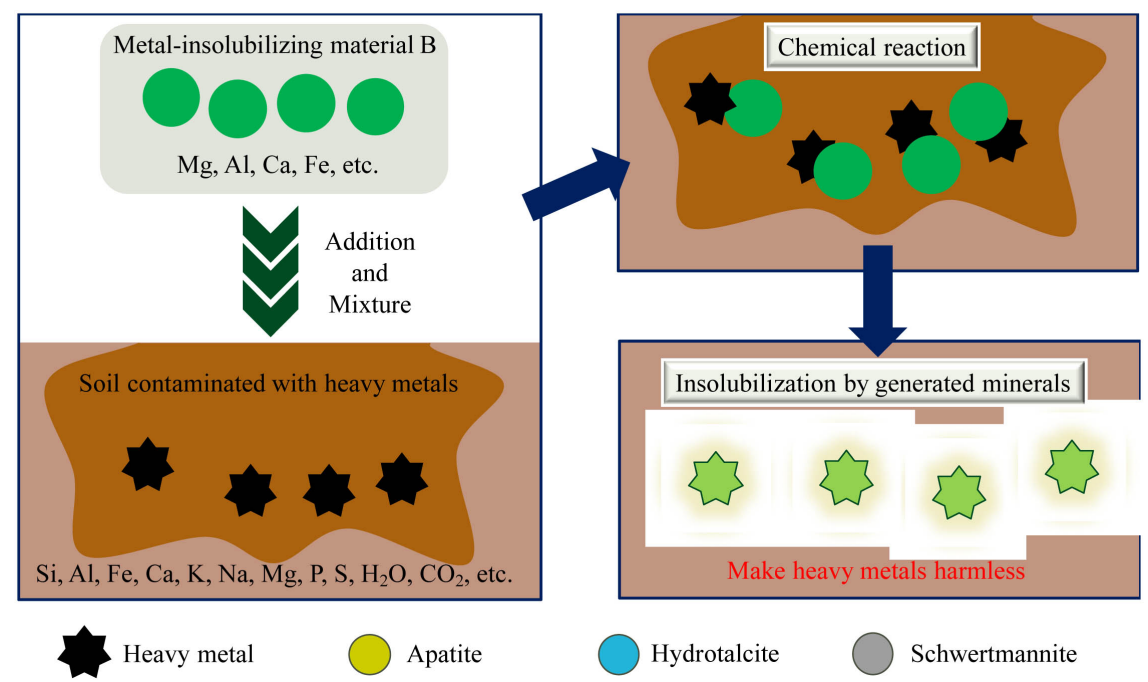

Figure 10. Insolubilization mechanism by metal-insolubilizing material B.

\section{a) Insolubilization by schwertmannite}

After the addition of the metal-insolubilizing material, the iron component, the sulfuric acid component, and the water in the soil cause a chemical reaction, whereby schwertmannite is generated. Schwertmannite is a metastable phase mineral of goethite, but its solubility decreases due to adsorb anions, such as arsenate ions, and it becomes structurally stable [19] [20].

Regarding the insolubilization mechanism, it is thought that the sulfate ions in the schwertmannite are exchanged for arsenate $\left(\mathrm{H}_{2} \mathrm{AsO}_{4}^{2-}\right)$ ions or the like due to the anion exchange reaction (ligand exchange reaction) and that arsenic is adsorbed, as shown in Figure 11.

The selectivity of oxy anion species on schwertmannite-holding sulfate ions is "arsenate ion > chromate ion > selenate ion"; arsenate ions are preferentially adsorbed [21]. In addition, the phase change time from schwertmannite to goethite is also long in the above order, and the retention stability of adsorbed oxy anion species is also high in the above order [22] [23].

Therefore, schwertmannite is a long-term stable mineral especially for arsenate ions.

\section{b) Insolubilization by hydrotalcite}

After the addition of the metal-insolubilizing material, the magnesium component, the aluminium component, and the water in the soil cause a chemical reaction whereby hydrotalcite is generated.

Hydrotalcite has a host layer which is a positively charged octahedral layer formed by substituting $\mathrm{Al}^{3+}$ for a part of $\mathrm{Mg}^{2+}$ of $\mathrm{Mg}(\mathrm{OH})_{2}$, and a guest layer which is composed of an anion and interlayer water compensating for this positive charge. Hydrotalcite has a structure in which it is alternately stacked with host layers and guest layers [23].

Regarding the insolubilization mechanism, when the positively charged host layer of hydrotalcite is formed, heavy metal anions, such as water, arsenate ions, 
selenate ions, and the like, are adsorbed into the guest layer, as shown in Figure 12.

That is, heavy metal anions are physically (electrically) adsorbed between the hydrotalcite layers; and thereafter, there is a risk of the heavy metal anions re-elution when the heavy metal anions are exchanged for other anions. However, if the heavy metal anions form inner sphere complexes with hydrotalcite surfaces after physisorption, the possibility of re-elution greatly decreases.

\section{c) Insolubilization by apatite}

After the addition of the metal-insolubilizing material, the calcium component, the phosphoric acid component, and the water in the soil cause a chemical reaction whereby apatite is generated.

For insolubilization by apatite, hydroxyapatite is firstly formed, and then heavy metals are insolubilized by the substitution reaction between the hydroxyapatite and the heavy metal ions. Therefore, insolubilization progresses in stages, so it is thought that the above-described sorption occurs. In other words, it is conceivable that heavy metal ions are adsorbed on the surface of hydroxyapatite and afterwards incorporated into hydroxyapatite, resulting in the formation of apatite crystals containing heavy metals, as shown in Figure 8.

Hydroxyapatite is represented by $\mathrm{Ca}_{5}\left(\mathrm{PO}_{4}\right)_{3}(\mathrm{OH})$, which can be expected to insolubilize many hazardous substances, such as lead, cadmium and arsenic. The reaction is shown below.

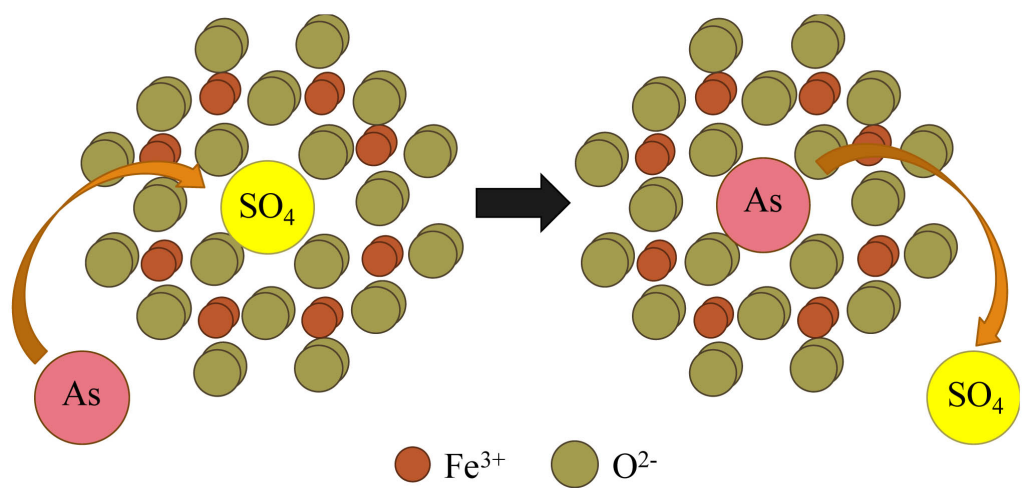

Figure 11. Insolubilization mechanism by schwertmannite.

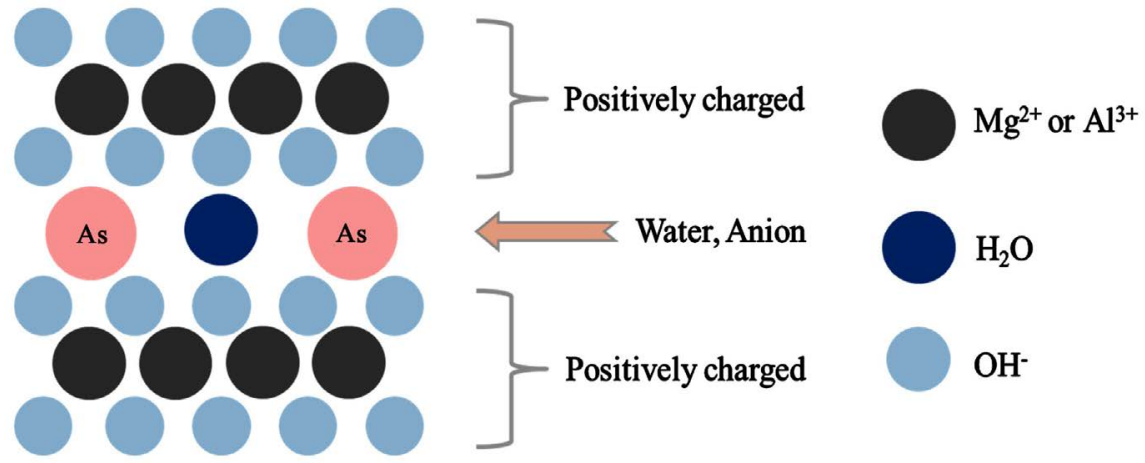

Figure 12. Insolubilization mechanism by hydrotalcite. 
Regarding the insolubilization mechanism for lead and cadmium, lead ions $\left(\mathrm{Pb}^{2+}\right)$ which are present in an unstable state in the soil are stabilized and insolubilized by substituting them for calcium ions $\left(\mathrm{Ca}^{2+}\right)$ in hydroxyapatite. In addition, since divalent heavy metal cations show a common behavior, it is thought that cadmium ions $\left(\mathrm{Cd}^{2+}\right)$ are likewise insolubilized, as seen in Equations (1) and (2).

$$
\begin{gathered}
\mathrm{Ca}_{5}\left(\mathrm{PO}_{4}\right)_{3} \mathrm{OH}+5 \mathrm{~Pb}^{2+} \rightarrow \mathrm{Pb}_{5}\left(\mathrm{PO}_{4}\right)_{3} \mathrm{OH}+5 \mathrm{Ca}^{2+} \\
\mathrm{Ca}_{5}\left(\mathrm{PO}_{4}\right)_{3} \mathrm{OH}+5 \mathrm{Cd}^{2+} \rightarrow \mathrm{Cd}_{5}\left(\mathrm{PO}_{4}\right)_{3} \mathrm{OH}+5 \mathrm{Ca}^{2+}
\end{gathered}
$$

Regarding the insolubilization mechanism for arsenic, the arsenate ions $\left(\mathrm{AsO}_{4}^{3-}\right)$ which are present in an unstable state in alkaline soil are stabilized and insolubilized by substituting them for phosphate ions $\left(\mathrm{PO}_{4}^{3-}\right)$ in hydroxyapatite, as seen below (Equation (3)).

$$
\mathrm{Ca}_{5}\left(\mathrm{PO}_{4}\right)_{3} \mathrm{OH}+3 \mathrm{AsO}_{4}^{3-} \rightarrow \mathrm{Ca}_{5}\left(\mathrm{AsO}_{4}\right) \mathrm{OH}+3 \mathrm{PO}_{4}^{3-}
$$

\section{Conclusions}

\subsection{Insolubilization Effect}

In this study, a leaching test, a $\mathrm{pH}$ test, and an acid or alkali addition leaching test were performed on metal-insolubilizing materials $\mathrm{A}$ and $\mathrm{B}$ with different main components to confirm the insolubilization effect.

When the target soil was acidic and the insolubilization treatment was performed using metal-insolubilizing material $\mathrm{A}$, a sufficient insolubilization effect was obtained for the complex contaminated soil and the treated soil was neutralized. When the target soil was alkaline and the insolubilization treatment was performed using both metal-insolubilizing materials $\mathrm{A}$ and $\mathrm{B}$, a sufficient insolubilizing effect on arsenic was obtained for each metal-insolubilizing material, but the $\mathrm{pH}$ of the soil after the insolubilization treatment was different. In addition, only metal-insolubilizing material B was able to bring about a long-term insolubilization effect.

\subsection{Insolubilization Mechanism}

In this study, the insolubilization mechanism was clarified from chemical and mineralogical considerations based on the data obtained from the tests. Then, based on phenomena such as adsorption, absorption, and sorption, attention was focused on insolubilization by minerals, such as schwertmannite, hydrotalcite, and apatite.

Moreover, as insolubilization by other minerals and compounds is also conceivable, further consideration is necessary.

\subsection{Future Tasks}

Although the insolubilization effect could be confirmed in this study, it was not possible to identify the compounds present in the soil after insolubilization 
treatment. Therefore, in order to confirm the compounds in the soil in detail, it will be necessary to perform an analysis using an electron microscope and so on, together with an X-ray analysis.

In addition, metal-insolubilizing materials with different compositions and compounding ratios were prototyped, and the insolubilization effect on soil contaminated with heavy metals under various conditions was confirmed. As a result, the metal-insolubilizing materials could be improved.

\section{References}

[1] Ministry of the Environment (MOE) (2002) Government of Japan: Soil Contamination Countermeasures Act. Act No. 53 of May 29, 2002.

[2] Arao, T., Ishikawa, S., Murakami, M., Abe, K., Maejima, Y. and Makino, T. (2010) Heavy Metal Contamination of Agricultural Soil and Countermeasures in Japan. Paddy Water Environment, 8, 247-257. https://doi.org/10.1007/s10333-010-0205-7

[3] Sakamoto, D. (2011) The Enforcement of the Revised Soil Contamination Countermeasures Act. Japan Technical Association of the Pulp and Paper Industry Journal, 65, 1244-1248. (In Japanese)

[4] Pyle, K.B. (1975) The Ashio Copper Mine Pollution Case: Introduction: Japan Faces her Future. The Journal of Japanese Studies, 1, 347-350.

[5] Almeida, P. and Stearns, L. (1998) Political Opportunities and Local Grassroots Environmental Movement: The Case of Minamata. Social Problems, 45, 37-60.

[6] Tsunematsu, S., Uematsu, E., Saito, K. and Tamura, H. (2012) Immobilization of arsenic in Natural Soils by Gypsum Powder, Mechanistic Interpretations. Transactions of the Japanese Society of Irrigation, Drainage and Rural Engineering, 80, 141-150.

[7] Ministry of the Environment (MOE) and Government of Japan (2017). https://www.env.go.jp/council/10dojo/y105-02/ref01.pdf.07

[8] Paria, S. and Yuet, P.K. (2006) Solidification-Stabilization of Organic and Inorganic Contaminants Using Portland Cement: A Literature Review. Environmental Reviews, 14, 217-255.

[9] Shimaoka, T., Kuba, T., Nakayama, H., Fujita, T. and Horii, N. (2016) Basic Studies in Environmental Knowledge, Technology, Evaluation, and Strategy: Introduction to East Asia Environmental Studies. Springer, Berlin. https://doi.org/10.1007/978-4-431-55819-4

[10] Kanjo, Y. (1995) Leaching Test as the Screening for the Utilization of Waste. Proceedings of the 6 th Annual Conference of the Japan Society of the Waste Management Experts, Kobe, 16-18 October 1995, 741-743. (In Japanese)

[11] Malviya, R. and Chaudhary, R. (2006) Leaching Behavior and Immobilization of Heavy Metals in Solidified/Stabilized Products. Journal of Hazardous Materials, 137, 207-217. https://doi.org/10.1016/j.jhazmat.2006.01.056

[12] Sakai, S., Mizutani, S., Takatsuki, H. and Kishida, T. (1995) Study about the Leaching Test for the Waste-Availability Test and $\mathrm{pH}$-Dependent Test. Journal of the Japan Society of Waste Management Experts, 6, 225-234. (In Japanese)

[13] Krüger, O., Kalbe, U., Berger, W., Nordhauß, K., Christoph, G. and Walzel, H.P. (2012) Comparison of Batch and Column Tests for the Elution of Artificial Turf System Components. Environmental Science \& Technology, 46, 13085-13092.

[14] The Japanese Geotechnical Society (JGS) (2015) Japanese Geotechnical Society 
Standards: Laboratory Testing Standards of Geomaterials.

[15] Oyama, S., Okumura, M., Hoga, Y. and Nishimura, R. (2009) Solidification/Stabilization treatment with $\mathrm{MgO}$-Based Material. The Japanese Geotechnical Society Magazine, 57, 20-23. (In Japanese)

[16] Fukushi, K. and Sverjensky, D.A. (2007) A Surface Complexation Model for Sulfate and Selenate on Iron Oxides Consistent with Spectroscopic and Theoretical Molecular Evidence. Geochimica et Cosmochimica Acta, 71, 1-24.

[17] Fukushi, K. and Sverjensky, D.A. (2007) A Predictive Model (ETLM) for Arsenate Adsorption and Surface Speciation on Oxides Consistent with Spectroscopic and Theoretical Molecular Evidence. Geochimica et Cosmochimica Acta, 71, 3717-3745. https://doi.org/10.1016/j.gca.2007.05.018

[18] Fukushi, K. (2008) Modeling for Ion Adsorption on Clays. Journal of the Clay Science Society of Japan, 47, 93-103. (In Japanese)

[19] Inoue, A. and Hatta, T. (2006) Co-Precipitation Synthesis of Schwertmannite and Its Analogues with Different Anion Species, Focusing on Understanding of the Role of Anions in the Formation of FeOOH Mineral. Journal of the Clay Science Society of Japan, 45, 250-265. (In Japanese)

[20] Burton, E.D., Bush, R.T. and Sullivan, L.A. (2007) Reductive Transformation of Iron and Sulfur in Schwertmannite-Rich Accumulations Associated with Acidified Coastal Lowlands. Geochimica et Cosmochimica Acta, 71, 4456-4473. https://doi.org/10.1016/j.gca.2007.07.007

[21] Takada, M., Fukushi, K., Sato, T. and Yoneda, T. (2008) Adsorption of Oxyanions and Post-Adsorption Behavior of Schwertmannite. Journal of the Clay Science Society of Japan, 47, 255-260. (In Japanese)

[22] Wang, N., Oyama, S., Kataoka, M., Shinohara, T., Hata, T. and Miura, T. (2010) A Survey on Leaching Test for Heavy Metals: Immobilized Soil Using Acid or Alkaline Solution, Proceedings of the 16th Symposium on Groundwater Pollution and Its Management, Sendai, 17-18 June 2010, S4-S10. (In Japanese)

[23] Kameda, T., Yoshioka, T., Umetsu, Y. and Okuwaki, A. (2005) Application of Hydrotalcite for Water Environmental Preservation and Purification. The Chemical Times, 195, 10-16. (In Japanese) 